\title{
The A.R. Bergstrom Prize in Econometrics, 1996
}

We are pleased to announce the awarding of the A.R. Bergstrom Prize in Econometrics for 1996. The award is to Matthew Ryan, Department of Economics, the University Auckland, and a Ph.D. candidate at Yale University, for his paper "Aggregation Effects in Consumption."

The object of the Prize is to reward the achievement of excellence in econometrics, as shown by a research paper in any area of econometrics. The Prize is open to New Zealand citizens or permanent residents of New Zealand who, on the closing date for applications, have current or recent (i.e., within 2 years) student status for a higher degree. The Prize is awarded once every 2 years, with a value of $\mathrm{NZ} \$ 1,000$.

The citation that accompanies the award reads as follows:

Matthew Ryan's paper sets out a methodology for estimating the parameters of a micro-behavioural model of consumer expenditure decisions, using only aggregated data. The highlight of the analysis is the way in which it tightly combines economic theory and econometrics. It explicitly allows for heterogeneity across households and takes into account the effects of changes in the underlying income (total expenditure) distribution over time. The results obtained from New Zealand household expenditure data for the period 1988-1995, indicate the extent to which the proportions of the household budgets allocated to "food", "apparel" and "other goods" vary with total expenditure. These results also indicate the likely biases in forecasts and policy simulations from "representative agent" models.

The Adjundication Committee for the 1996 Award consisted of Professors Viv B. Hall and Andrew A. Weiss, of Victoria University of Wellington.

The Prize is supported by funds provided by the following sponsors:

\section{Institutional Sponsors:}

The New Zealand Association of Economists

The Faculty of Commerce and Economics at the University of Auckland The Department of Economics at the University of Canterbury

The Faculty of Commerce and Administration at Victoria University of Wellington

Lincoln University

The Department of Economics and Marketing at Lincoln University

Personal Sponsors:

C.R. Wymer

\author{
A.D. Brownlie \\ H.A. Fletcher \\ J.A. \& D:E.A. Giles \\ V.B. Hall \\ P.C.B. Phillips
}

R.J. Bowden

R.H. Court

Anonymous

D.M. Emanuel

In addition, royalties from the Festschrift Volume Models, Methods and Applications of Econometrics: Essays in Honour of A.R. Bergstrom, P.C.B. Phillips (ed.), Blackwell, Cambridge MA and Oxford UK, 1993, are applied to support the prize.

V.B. Hall \& P.C.B. Phillips

November 1996 